\title{
Memory capacity of a random, recurrently connected network of neurons with multiple, biologically realistic facilitation and adaptation profiles
}

\author{
Brian D DePasquale ${ }^{1 *}$, Stefano Fusi, ${ }^{1,2}$ \\ From Twentieth Annual Computational Neuroscience Meeting: CNS*2011 \\ Stockholm, Sweden. 23-28 July 2011
}

We developed a model of linear, integrate-and-fire neurons endowed with realistic firing rate facilitation and adaptation profiles (Figure 1B, green) based on parameters obtained from rodent cortical slice electrophysiology data [1]. The equations of dynamics of each model neuron contained facilitating and adapting currents, proportional to the intracellular concentration of different ionic species, which were modulated by each neuron's spiking history. The adapting input network projected in a feed-forward manner through a high dimensional, recurrently connected network of spiking neurons whose activity was then projected to a linear readout, firing-rate neuron. We sought to inspect the recurrently connected network's capacity for memory by injecting a time-varying "input signal" current into the adapting network (Fig. 1B, red) and training the weights
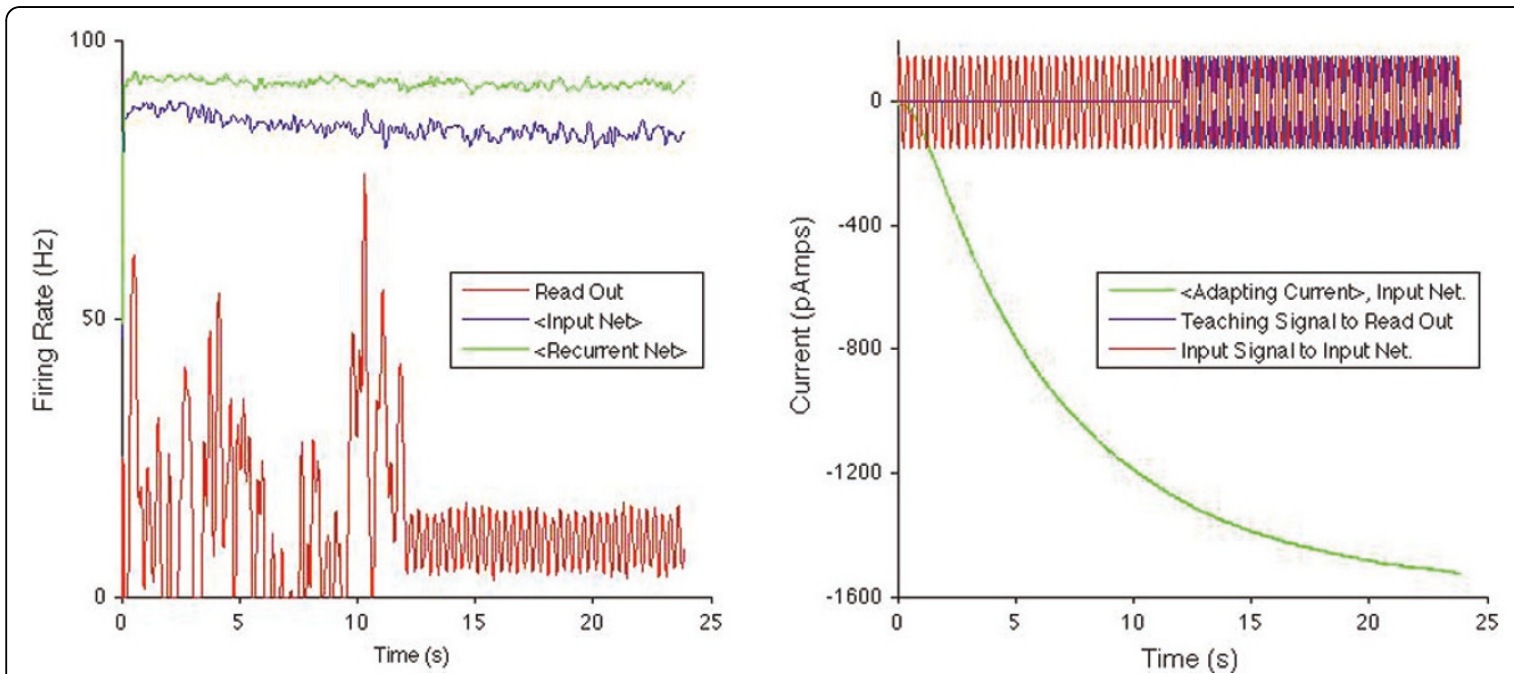

Figure 1 (A) Average firing rates $(<\bullet>)$ of recurrent and input networks, and trained linear read out neuron (B) Average adapting current, input and teaching currents

\footnotetext{
* Correspondence: bdd2107@columbia.edu

${ }^{1}$ Center for Theoretical Neuroscience, College of Physicians and Surgeons,

Columbia University, New York, NY, USA

Full list of author information is available at the end of the article
}

(c) 2011 DePasquale and Fusi; licensee BioMed Central Ltd. This is an open access article distributed under the terms of the Creative 
of the linear readout neuron so that its firing rate matched a teaching signal provided to the neuron; the teaching signal was a specified transformation of the input signal current to the adapting input network (Fig. 1B, blue).

Once trained, we could assess the memory capacity of the recurrently connected network. Specifically, we were interested in understanding the role of adaptation in extending the recurrently connected network's capacity to remember the input. The limits of memory capacity in recurrently connected neural networks have been studied previously [2-4] but in networks lacking realistic adaptation and facilitation profiles. Including these firing-rate dependent currents should fundamentally alter the time-scale of the network dynamics and the memory network's capacity for storing temporal signals. We studied the performance of the network for a variety of time varying signals and we analyzed its dependence on the inherent time constants of adaptation. We show one example in Figure 1A ,1B in which we found that the network is able to accurately generate a half-period time shifted version of a simple oscillatory input.

\section{Acknowledgments}

This work was supported by the Gatsby Foundation, the Kavli Foundation, DARPA SYNAPSE and the NSF Graduate Research Fellow Program.

\section{Author details}

'Center for Theoretical Neuroscience, College of Physicians and Surgeons, Columbia University, New York, NY, USA. ${ }^{2}$ Kavli Institute for Brain Science, Columbia University, New York, NY, USA.

Published: 18 July 2011

\section{References}

1. La Camera G, Rauch A, Thurbon D, Luscher HR, Senn W, Fusi S: Multiple time scales of temporal response in pyramidal and fast spiking cortical neurons. J. Neurophysiol 2006, 6:3448-3464.

2. Rigotti M, Rubin DBD, Wang X-J, Fusi S: Internal representation of task rules by recurrent dynamics: the importance of the diversity of neural responses. Front. of Comput. Neurosci 2010, 4:24.

3. Sussillo D, Abbott LF: Generating coherent patterns of activity from chaotic neural networks. Neuron 2009, 63:544-557.

4. White OL, Lee DD, Sompolinsky HS: Short-term memory in orthogonal neural networks. Phys. Rev. Lett 2004, 92(14):148102.

doi:10.1186/1471-2202-12-S1-P115

Cite this article as: DePasquale and Fusi: Memory capacity of a random, recurrently connected network of neurons with multiple, biologically realistic facilitation and adaptation profiles. BMC Neuroscience 201112 (Suppl 1):P115.

\section{Submit your next manuscript to BioMed Central} and take full advantage of:

- Convenient online submission

- Thorough peer review

- No space constraints or color figure charges

- Immediate publication on acceptance

- Inclusion in PubMed, CAS, Scopus and Google Scholar

- Research which is freely available for redistribution

Submit your manuscript at www.biomedcentral.com/submit
C Biomed Central 